\title{
Dexamethasone Improves Wound Healing by Decreased Inflammation and Increased Vasculogenesis in Mouse Skin Frostbite Model
}

\author{
Huiyin Tu, PhD; Dongze Zhang, MD; Aaron N. Barksdale, MD; Michael C. Wadman, MD; \\ Robert L. Muelleman, MD; Yu-Long Li, MD, PhD \\ Department of Emergency Medicine, University of Nebraska Medical Center, Omaha, NE
}

\begin{abstract}
Introduction-Frostbite is thought to result from initial vasoconstriction, ischemia, intracellular ice crystal formation, and inflammation caused by reperfusion injury. Corticosteroids have demonstrated beneficial anti-inflammatory effects in the treatment of other ischemia/reperfusion clinical conditions. The objective of this study was to determine the effect of dexamethasone (dex) on wound healing, inflammatory response, and vasculogenesis in a mouse skin frostbite model.

Methods - Treatment and control groups of C57/BL6 mice were subjected to frostbite using a previously described model. Treatment with intraperitoneal dex $\left(1 \mathrm{mg} \cdot \mathrm{kg}^{-1} \cdot \mathrm{d}^{-1}\right)$ began on the day of frostbite induction and lasted for $7 \mathrm{~d}$. Over $4 \mathrm{wk}$, we compared wound diameter; morphology by visual inspection, hematoxylin-eosin staining, and Masson's trichrome staining; density of inflammatory cytokines IL-1 $\beta$ and TNF $\alpha$ using Western blot analysis; and formation of microvasculature using immunofluorescence staining. Data were analyzed using 1-way or 1-way repeated-measures analysis of variance.

Results-After frostbite injury, morphological images demonstrated epidermal necrosis and loss in the frostbitten skin as well as infiltration of inflammation-related leukocytes. Increased production of inflammatory cytokines and disappearance of the microvasculature also occurred in the frostbitten skin. In comparison to the control group, treatment with dex promoted wound healing as demonstrated by decreased wound diameter; decreased levels of inflammatory cytokines, and accelerated formation of mature microvasculature.

Conclusions - In this animal model, dex improved wound healing in frostbitten skin and demonstrated both anti-inflammatory effects and stimulation of vasculogenesis. This study suggests that the use of potent anti-inflammatory agents may be an effective strategy for mitigating frostbite injury.
\end{abstract}

Keywords: animal, collagen, cytokine, ischemia, reperfusion, microvasculature

\section{Introduction}

Tissue injuries due to frostbite occur during both freezing and thawing. During freezing, intracellular and extracellular crystal formation results in rupture of cell membranes. This causes damage to tissue proteins and lipids, resulting in dehydration of cells and alteration in intracellular electrolyte concentrations. ${ }^{1,2}$ During thawing, similar to other

Huiyin Tu and Dongze Zhang contributed equally to this work.

Corresponding author: Robert L. Muelleman, MD, Department of Emergency Medicine, University of Nebraska Medical Center, 981150 Nebraska Medical Center, Omaha, NE 68198-1150; e-mail: rmuellem@unmc.edu.

Submitted for publication December 2019.

Accepted for publication July 2020. types of ischemia-reperfusion (IR) injuries, disrupted microvascular flow, thrombosis, and inflammation further exacerbate tissue damage. This results in endothelial cell damage, destruction of microvasculature, and interstitial edema. ${ }^{3-5}$ Because frostbite injury can cause tissue destruction and permanent disability, ${ }^{6,7}$ it is important to find additional treatment options.

In the 2019 Wilderness Medical Society guideline update for the prevention and treatment of frostbite, the only recommendation for hospital treatment that was based on high level of evidence was rapid rewarming. ${ }^{8}$ All other recommendations were based on a low or very low quality of evidence. ${ }^{9}$ A possible explanation for the lack of high-quality evidence is the difficulty of matching treatment and control groups in clinical studies and a lack 
of reliable animal models for frostbite injuries. This has limited the opportunity to study new treatments. ${ }^{10-15}$

Recent advances in frostbite treatment involve increasing perfusion of frostbitten tissue with thrombolytic drugs such as a tissue plasminogen activator ${ }^{16-19}$ or prostacyclin vasodilators such as iloprost. ${ }^{20,21}$ Current recommendations to mitigate inflammatory injury from reperfusion have been limited to the use of nonsteroidal anti-inflammatory drugs such as ibuprofen. ${ }^{8}$

Evidence from studies evaluating thermal burn and tourniquet-induced skeletal muscle IR injuries have suggested benefits from treatment with steroids. ${ }^{22-27}$ Inflammatory cells (polymorphonuclear leukocytes and mast cells) have been identified in the frostbitten skin of rabbit ears. ${ }^{25}$ Increased levels of proinflammatory cytokines have been identified in humans with frostbite injuries. ${ }^{26}$ These studies prompted our investigation of the role of inflammation in mitigating the severity of frostbite injuries.

Glucocorticoid drugs such as dexamethasone (dex) have a potent anti-inflammatory effect. High-dose administration of glucocorticoids for extended periods of time ( $>60 \mathrm{~d}$ ) can be associated with serious side effects such as increased blood glucose and osteoporosis. ${ }^{28-30} \mathrm{~A}$ recent study showed that short-term treatment with dex $\left(1 \mathrm{mg} \cdot \mathrm{kg}^{-1} \cdot \mathrm{d}^{-1}\right)$ for $7 \mathrm{~d}$ significantly decreased inflammatory response and improved skeletal muscle contractile function in a mouse hindlimb tourniquet-induced IR model. ${ }^{31}$ Using a validated mouse model of skin frostbite injury, ${ }^{10}$ the current study investigated the effects of dex on frostbite-induced skin injuries and whether inflammation-related leukocyte infiltration and proinflammatory cytokines are involved in frostbite injury.

\section{Methods}

\section{ANIMALS}

Fifty-eight C57/BL6 mice weighing 22 to $25 \mathrm{~g}$ (Charles River Laboratory, Wilmington, MA) were used in this study, with 5 to 8 mice in each experimental group. The mice were housed in conditions of controlled temperature and humidity with a 12:12-h dark-light cycle and were provided water and mouse chow ad libitum. All experimental procedures were approved by the University of Nebraska Medical Center institutional animal care and use committee and were carried out in accordance with the National Institutes of Health (NIH Publication No. 85-23, revised 1996) and the American Physiological Society's "Guides for the Care and Use of Laboratory Animals."

\section{MOUSE MODEL OF FROSTBITE}

We used a recently described mouse frostbite model. ${ }^{10}$ Male and female C57BL6 mice (22-25 g) were randomly assigned to the frostbite without dex, frostbite with dex, or sham group. The sham group was used to identify any changes that might have resulted from anesthesia, intraperitoneal injection, or magnet placement.

Under anesthesia (2\% isoflurane inhalant), the dorsal skin surface from the base of the neck to the top of the rear haunches was shaved. The skin was cleansed with a $70 \%$ isopropyl alcohol swab. A circle of uniform diameter $(2.5 \mathrm{~cm})$ was permanently marked using indelible black ink. Ceramic (ferrite) magnets (diameter $1.27 \mathrm{~cm}$, thickness $0.64 \mathrm{~cm})$ were placed in crushed dry ice $\left(-78.5^{\circ} \mathrm{C}\right)$ and allowed to cool for $15 \mathrm{~min}$. The back skin of the mouse was lifted by fingers into a skin fold, and 2 frozen magnets were placed so that they adhered from opposite sides of the fold. A silicone barrier was then slid underneath the magnets as a thermal shield to limit the decline in body temperature. A set of 2 frozen magnets was left in place for $1 \mathrm{~min}$ and then removed to allow a new set of 2 magnets to be placed in the same location. Exchange time for the magnets was less than $2 \mathrm{~s}$ to minimize skin thawing. Total freezing time was approximately $5 \mathrm{~min}$. Finally, the skin was allowed to thaw completely, and anesthesia was ended. Sham-operated mice underwent the same protocol without freezing of the skin (room temperature magnets). During the procedure, a heating pad (ATC 2000; World Precision Instruments, Sarasota, FL) was used to maintain body temperature at $37^{\circ} \mathrm{C}$ until the mice woke.

\section{DRUG TREATMENT}

Dex (Sigma-Aldrich, St. Louis, MO) was dissolved in $0.9 \%$ $\mathrm{NaCl}$. Frostbitten mice were randomly divided into 2 groups for intraperitoneal administration of normal saline or dex $\left(1 \mathrm{mg} \cdot \mathrm{kg}^{-1} \cdot \mathrm{d}^{-1}\right)$. Intraperitoneal injection is a quick, safe, and repeatable delivery mechanism for small animals and allows for substances to be rapidly absorbed. Treatment with normal saline solution or dex $(0.2 \mathrm{~mL}$, once daily) was initiated immediately after the removal of the magnets and continued daily for a total of $7 \mathrm{~d}$.

\section{WOUND SURFACE ANALYSIS}

A total of 19 mice were used for wound surface analysis. There were 6 mice in the sham group, 8 mice in the frostbite without dex group, and 5 mice in the frostbite with dex group. On Days 1, 3, 7, 14, 21, and 28, skin hair was gently shaved outside the border of the wound to allow clear visualization of the injured skin. Digital photographs of the wounds were taken before and 5 min after magnet removal and once on each of the other $6 \mathrm{~d}$. The wound was considered to be healed when the frostbitten skin appeared normal. The wound size is reported as wound diameter at the different experimental time points. Morphologic changes of the frostbitten skin, such as skin color, swelling, and 
ulcer development, were assessed by visual observation. On Day 28, the mice were euthanized following the approved euthanasia protocol, and the skin of the mouse's back was harvested for subsequent measurements. Fifteen mice (5 from each group) used in the wound surface analysis were included in the Week 4 histologic evaluation, Western blot analysis, and immunofluorescence staining described next.

\section{ALLOCATION OF ANIMALS FOR HISTOLOGIC EVALUATION, WESTERN BLOT ANALYSIS, AND IMMUNOFLUORESCENCE STAINING}

A total of 54 mice (including 15 mice used in the wound surface analysis just described) were equally distributed into the sham, frostbite without dex, and frostbite with dex groups ( $\mathrm{n}=18$ mice in each group). At Weeks 1,2 , and 4 , the mice were euthanized ( $n=6$ mice at each time point in each group) following the approved euthanasia protocol. The skin from the back of all mice was removed for measurements described in the following.

\section{HISTOLOGIC EVALUATION}

The harvested skins were fixed in Methacarn solution (300 $\mathrm{mL}$ methanol, $150 \mathrm{~mL}$ chloroform, and $50 \mathrm{~mL}$ acetic acid) for $48 \mathrm{~h}$ and $60 \%$ ethanol for $72 \mathrm{~h}$. The fixed skin was embedded into paraffin wax after routine processing and then cut into 4- $\mu \mathrm{m}$-thick cross-sections. After deparaffinization, sections were stained with hematoxylin and eosin (Sigma-Aldrich) or with Masson's trichrome (SigmaAldrich). Stained sections were captured by a bright-field microscope (Zeiss Oberver Z1) with a digital camera (Axiocam 105 Color).

\section{PROTEIN EXPRESSION OF INFLAMMATORY CYTOKINES IL-1 $\beta$ AND TNF $\alpha$ IN FROSTBITTEN SKIN}

The harvested skin from all mice was stored at $-80^{\circ} \mathrm{C}$ until Western blot analysis. A lysing buffer of $10 \mathrm{mM}$ tris (hydroxymethyl) aminomethane, $1 \mathrm{mM}$ ethylenediaminetetracetic acid, $150 \mathrm{mM} \mathrm{NaCl}, 1 \%$ sodium dodecyl sulfate, $1 \mathrm{mM}$ phenylmethylsulfonyl fluoride ( $\mathrm{pH}$ 7.4), and protease inhibitor cocktail (100 $\mu \mathrm{L} \cdot \mathrm{mL}^{-1}$; P2714, Sigma-Aldrich) was added to the skin tissue for homogenization. Homogenized skin tissue was centrifuged at $12,000 \mathrm{~g}$ for $20 \mathrm{~min}$ at $4^{\circ} \mathrm{C}$. Total protein concentration in the supernatant was measured by a bicinchoninic acid protein assay kit (Thermo Fisher Scientific, Waltham, MA). The same volume of loading buffer was added to protein samples and mixed and heated for $5 \mathrm{~min}$ at $100^{\circ} \mathrm{C}$. Protein samples $(40 \mu \mathrm{g}$ per well) loaded in the stacking gel were separated on a $12 \%$ sodium dodecyl sulfate-polyacrylamide running gel. Proteins from these samples were electrophoretically transferred at $200 \mathrm{~mA}$ for 3 $\mathrm{h}$ onto a polyvinylidene fluoride membrane (EMD Millipore, Billerica, MA). The membrane was blocked with 5\% nonfat milk for $1 \mathrm{~h}$. Then the membrane was probed with rabbit anti TNF- $\alpha$ antibody (MM350C, Thermo Fisher Scientific), mouse anti IL-1 $\beta$ antibody (MM425B, Thermo Fisher Scientific), or mouse anti $\beta$-actin antibody (sc-47778, Santa Cruz Biotechnology, Dallas, TX) overnight at $4^{\circ} \mathrm{C}$. After washing by phosphate-buffered saline, the membrane was incubated with peroxidase-conjugated goat anti-rabbit IgG (31460, Thermo Fisher Scientific) or goat anti-mouse IgG (31430, Thermo Fisher Scientific) for $1 \mathrm{~h}$. The signal was developed by enhanced chemiluminescence substrate (Thermo Fisher Scientific) and captured by UVP bioimaging system (UVP, Upland, CA).

\section{EVALUATION OF VASCULOGENESIS THROUGH IMMUNOFLUORESCENCE STAINING OF CD31}

Skin vasculogenesis was measured by immunofluorescence staining and Western blot analysis of CD31, which is a vascular endothelial cell marker indicating vasculogenesis. ${ }^{32-34}$ The harvested skin from all mice was fixed with $4 \%$ paraformaldehyde for $12 \mathrm{~h}$ and then soaked in $30 \%$ sucrose for $12 \mathrm{~h}$ at $4^{\circ} \mathrm{C}$ for cryostat procedure. The skin was cut into $14-\mu \mathrm{m}$-thick cross-sections in a freezing cryostat (Leica $\mathrm{CM} 3050 \mathrm{~S})$ at $-20^{\circ} \mathrm{C}$. Skin tissue sections were permeabilized with $0.3 \%$ Triton X-100 (Thermo Fisher Scientific) in phosphate-buffered saline at room temperature for $20 \mathrm{~min}$. After skin tissue sections were successively incubated with $10 \%$ normal donkey serum (Jackson Immunoresearch Labs Inc.), rabbit antiCD31 antibody (ab28364, Abcam, Cambridge, MA), and donkey anti-rabbit IgG labelled with Alexa Fluor 594 (A21207, Thermo Fisher Scientific), tissue images were captured using a Leica fluorescent microscope (Zeiss Observer Z1) with a digital camera (Axiocam 503 Mono).

\section{STATISTICAL ANALYSIS}

All data are presented as mean \pm SD. SigmaPlot 12 was used for data analysis. Statistical significance was determined by unpaired t-test for single comparison between 2 groups. A 1-way analysis of variance with post hoc Dunnett's test or 1-way repeated-measures analysis of variance with post hoc Dunnett's test was used to determine statistical significance for multigroup comparisons. Normal distribution of data was confirmed with the Kolmogorov-Smirov test and 
A. Representative image in a single mouse per group
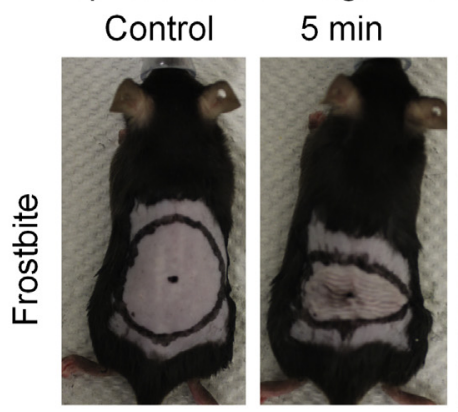

$1 \mathrm{~d}$

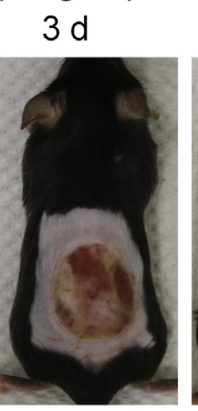

1 wk

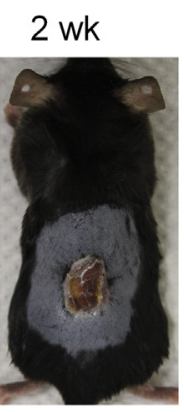

$3 w k$

4 wk
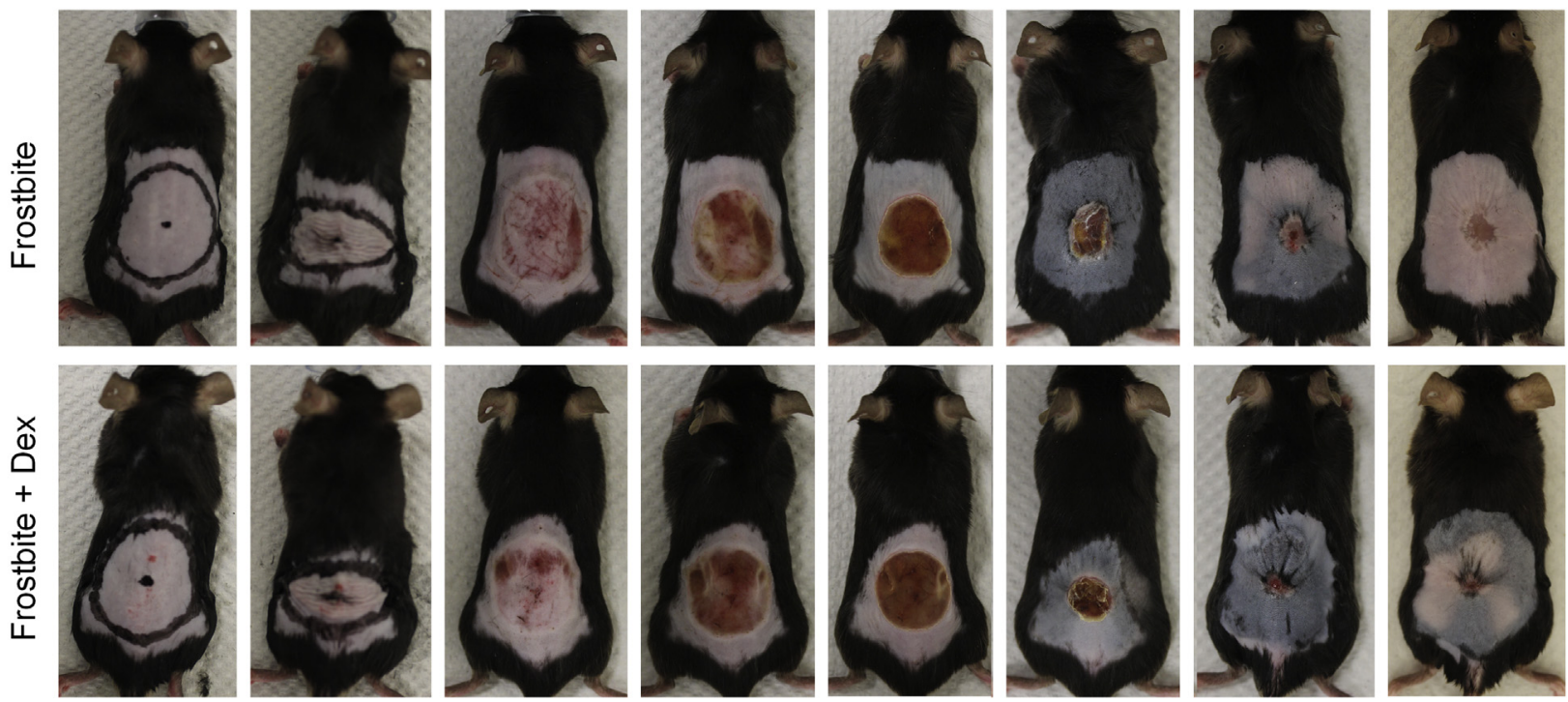

B. Mean data in frostbite and frostbite plus dexamethasone (Dex) groups

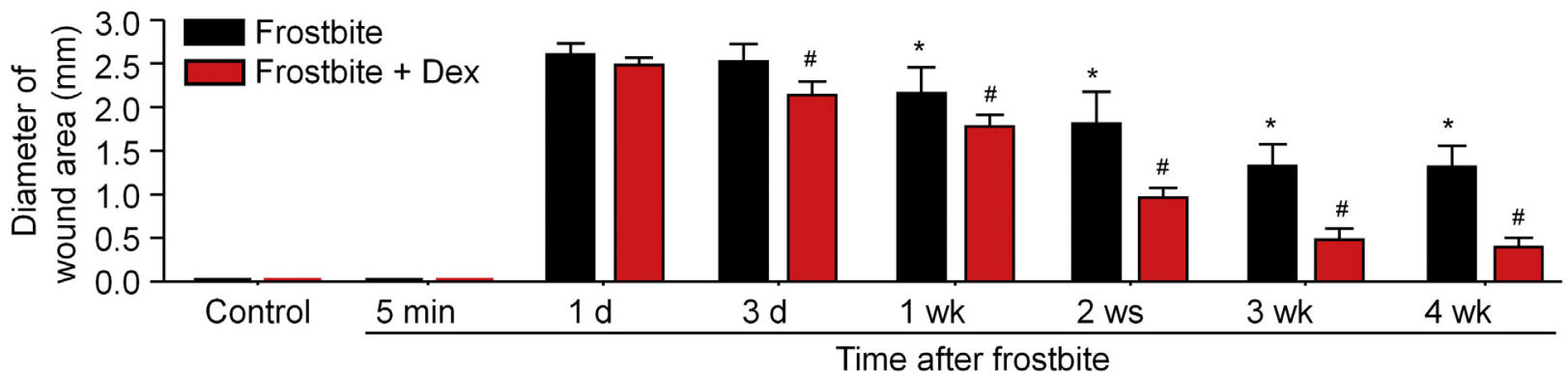

Figure 1. Representative (A) and mean data (B) for progression of the skin wound after the 5-min continuous dry-ice freeze in frostbite without dexamethasone (dex) and frostbite with dex groups of mice. Data are mean $\pm \mathrm{SD}$. N=8 mice in frostbite without dex group and 5 mice in frostbite with dex group. ${ }^{*} P<0.05$ vs 1 -d frostbite. ${ }^{\#} P<0.05$ vs frostbite without dex group at the same time point.

equal variance with Levene's test. Statistical significance was defined as $P<0.05$.

\section{Results}

\section{WOUND HEALING}

Visually, after 5 min of freezing, there were fine wrinkles on surface of the frozen skin, but no change in color. At Day 1 after frostbite, a wound had appeared, leaving the skin visibly red and swollen. At Day 3, the surface tissue of the skin had been replaced with an ulcer. After the first week postfrostbite, wound healing had begun with the formation of an eschar. Wound healing continued throughout the following $3 \mathrm{wk}$ (Figure 1A and B). None of these changes occurred in the sham group, which had the magnets placed at room temperature.
In the dex treatment group, we began to observe wound healing of the frostbitten skin on Day 3, which was significantly accelerated compared to the frostbite without dex group. Specifically, the diameter of the wound area was smaller at all measured endpoints, beginning at Day 3 and continuing through the end of the 4-wk study period (Figure 1A and B).

\section{EFFECTS OF DEX ON HISTOPATHOLOGY}

Normal skin harvested from a sham-treated mouse demonstrates 4 layers with clear margins: epidermis, dermis, adipose tissue (panniculus adiposus), and skeletal muscle (panniculus carnosus) (Figure 2). Collagen was evenly distributed in the dermis (Figure 3). In the frostbite without dex group, at $1 \mathrm{wk}$, the epidermis had disappeared, and there was inflammation-related leukocyte infiltration in 


\section{Frostbite}
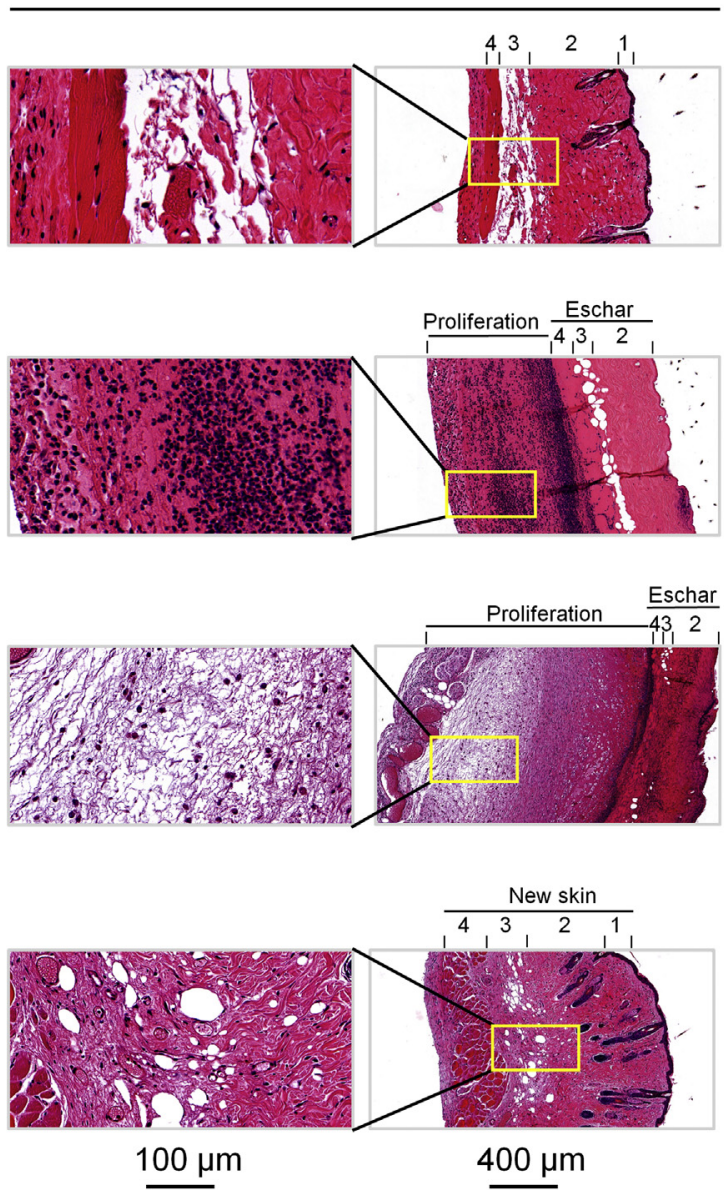

Frostbite+Dex
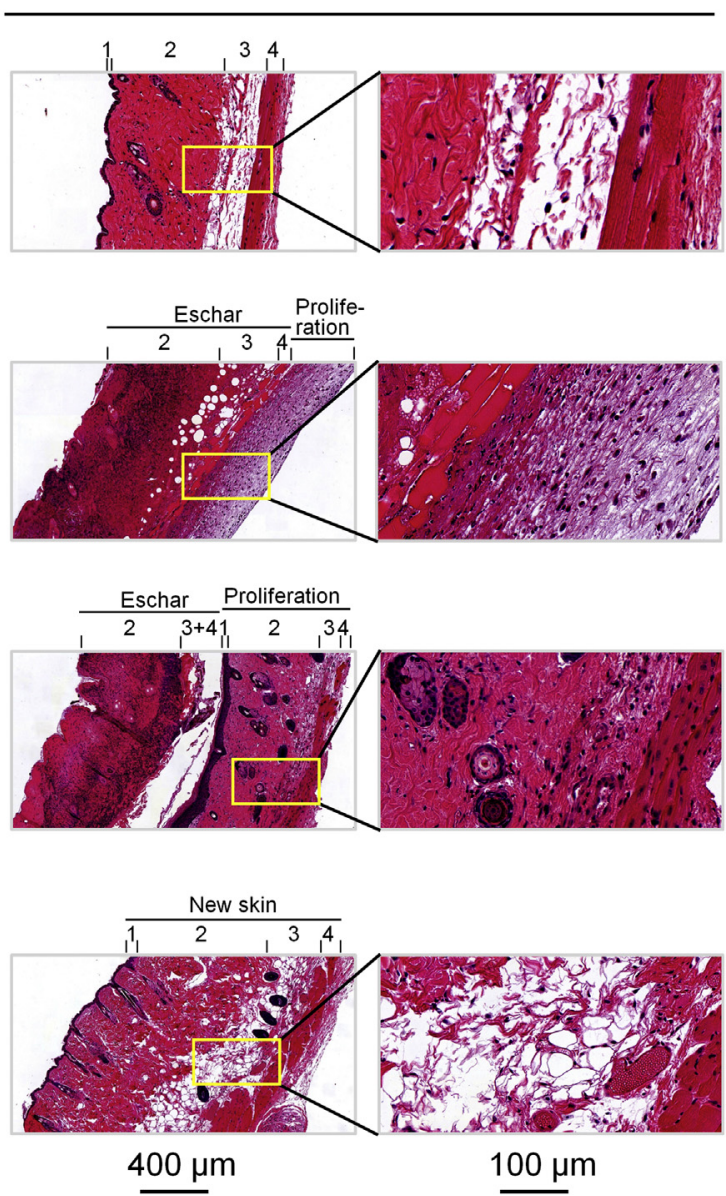

Figure 2. Representative histological images of the skin at control and different periods after the frostbite $(1,2$, and 4 wk) in frostbite without dexamethasone and frostbite with dexamethasone groups. The different layers of the skin are numbered: epidermis (1), dermis (2), adipose tissue (3), and skeletal muscle (4).

the proliferated tissue under the eschar (Figures 2 and 3). Collagen was still present in the dermis of the eschar, with a small amount in the proliferated tissue (Figure 3). At 2 wk postfrostbite, the eschar remained, and the tissue proliferation had become more visible with an unclear separation of skin layers. The inflammation-related leukocyte infiltration had begun to resolve (Figure 2), and collagen deposition was significantly decreased in the eschar (Figure 3). At 4 wk postfrostbite, the eschar was gone and an immature new skin layer had formed with mild collagen deposition (Figures 2 and 3).

In the frostbite with dex treatment group, at $1 \mathrm{wk}$ postfrostbite, there was markedly inhibited inflammationrelated leukocyte infiltration in the proliferated tissue (Figure 2). In addition, at $2 \mathrm{wk}$ postfrostbite, there was increased tissue proliferation, including a clear separation of skin layers, the formation of hair follicles and sebaceous glands, and more collagen deposition in the proliferated tissue (Figures 2 and 3). Finally, at 4 wk postfrostbite, new mature skin had formed with evenly distributed collagen in the frostbitten area (Figures 2 and 3).

\section{EFFECTS OF DEX ON INFLAMMATORY CYTOKINES}

In sham mice, expression of IL- $1 \beta$ and TNF $\alpha$ remained at a low level (Figure 4). At $1 \mathrm{~d}$ postfrostbite, there was no significant change in expression of IL- $1 \beta$ and TNF $\alpha$ (data not shown). The levels of IL-1 $\beta$ and TNF $\alpha$ began to increase 3 $\mathrm{d}$ postfrostbite, reaching maximum levels after Week 1 . The peak levels persisted through the second week, before returning to near the sham level at the end of the fourth week (Figure 4). Treatment with dex significantly decreased the IL- $1 \beta$ and TNF $\alpha$ levels through the first 2 wk, although there was a slight increase compared to the 


\section{Frostbite}
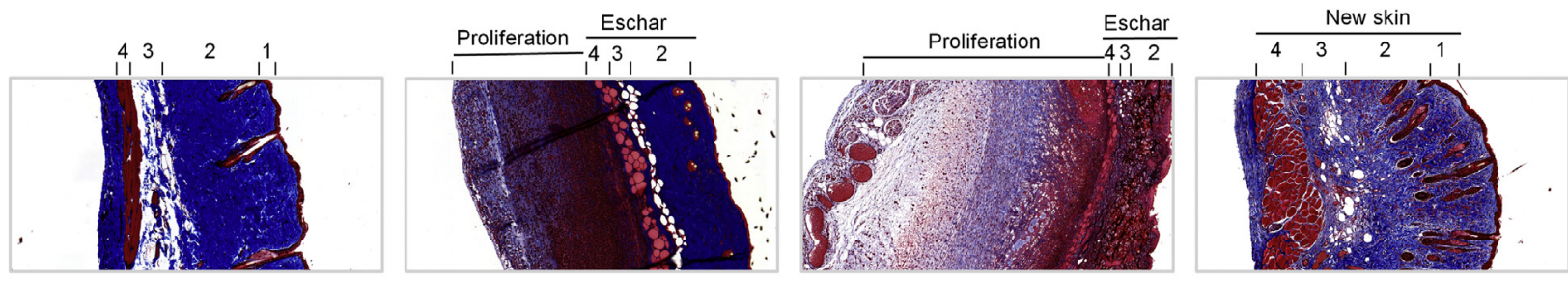

\section{Frostbite+Dex}

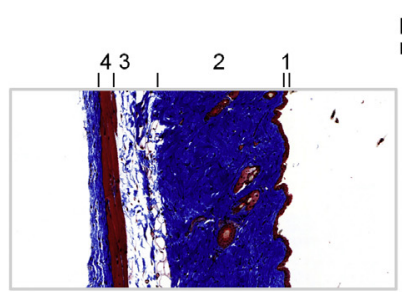

Control

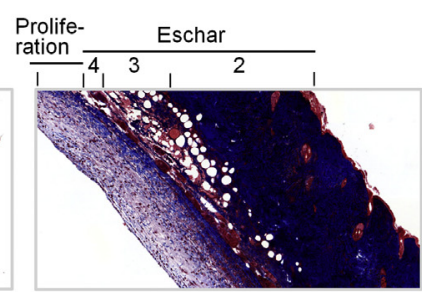

$1 \mathrm{wk}$

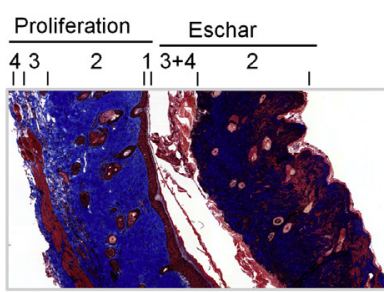

$2 w k$
$4 \overline{00 \mu \mathrm{m}}$

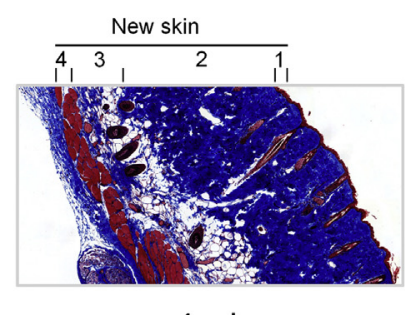

4 wk

Figure 3. Representative histologic images of the skin at control and different periods after frostbite $(1,2$, and 4 wk) in frostbite without dexamethasone and frostbite with dexamethasone groups. Blue represents collagen fibers in the skin. The different layers of the skin are numbered: epidermis (1), dermis (2), adipose tissue (3), and skeletal muscle (4).

frostbite without dex group at the end of the study period (Figure 4).

\section{THE EFFECTS OF DEX ON VASCULOGENESIS}

At Days 1 and 3 postfrostbite, the expression of CD31 was very low in both frostbite groups, suggesting that the microvasculature in the skin had been significantly damaged (data not shown). In the frostbite without dex group, the expression of CD31 began to increase at $1 \mathrm{wk}$ and gradually reached a near-baseline level by Week 4 (Figure 5B). Although the expression of CD31 nearly returned to baseline level, the density of microvascular CD31 seen in immunofluorescence staining remained low (Figure 5A).

In the frostbite with dex group, CD31 levels were significantly higher at Week 1 and through the end of the study when compared to the frostbite without dex group (Figure 5B). In addition, the frostbite with dex group demonstrated increased density of microvascular CD31 on immunofluorescence staining, with levels exceeding those seen in the frostbite without dex group (Figure 5A).

\section{Discussion}

Although documented evidence of frostbite can be traced back for millennia, ${ }^{35}$ effective therapeutic treatments have remained elusive. A lack of reliable preclinical animal models to explore the cellular and molecular mechanisms of frostbite injuries has slowed the discovery of new and effective interventions. ${ }^{3,4,10-14,36-51}$ A recently described mouse model of frostbite ${ }^{10}$ may be an efficient, reliable, and reproducible model for evaluating new treatments and investigating cellular and molecular mechanisms associated with frostbite.

Using this model, we found no skin injury in the sham group as a result of pressure to the skin caused by the magnets at room temperature, suggesting that the magnets alone did not contribute to the injury patterns seen in the 2 frostbite groups. In the frostbite without dex group, we demonstrated not only morphologic damage but also inflammation-related leukocyte infiltration, overproduction of inflammatory cytokines, and disappearance of the microvasculature in the frostbitten skin. Slow spontaneous wound healing was initially seen at $1 \mathrm{wk}$ and demonstrated a combination of immature new skin with mild collagen deposition and immature microvasculature formation throughout the 4-wk study period. In the frostbite with dex group, dex inhibited inflammation-related leukocyte infiltration, decreased levels of inflammatory cytokines, promoted collagen deposition, accelerated the formation of mature microvasculature, and promoted increased wound healing when compared to the frostbite without dex group. These results suggest that wound healing may be improved by mitigation of inflammation and stimulation of vasculogenesis.

Although most frostbite treatment guidelines (including the Wilderness Medical Society guidelines ${ }^{8}$ ) recommend nonsteroidal anti-inflammatory drugs, glucocorticoids 
A. Raw data

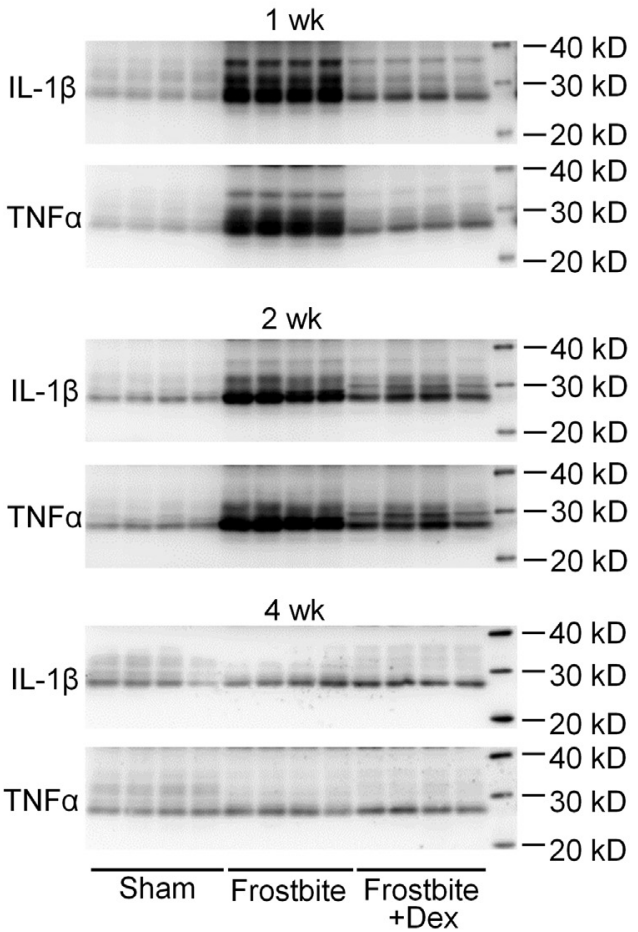

B. Mean Data
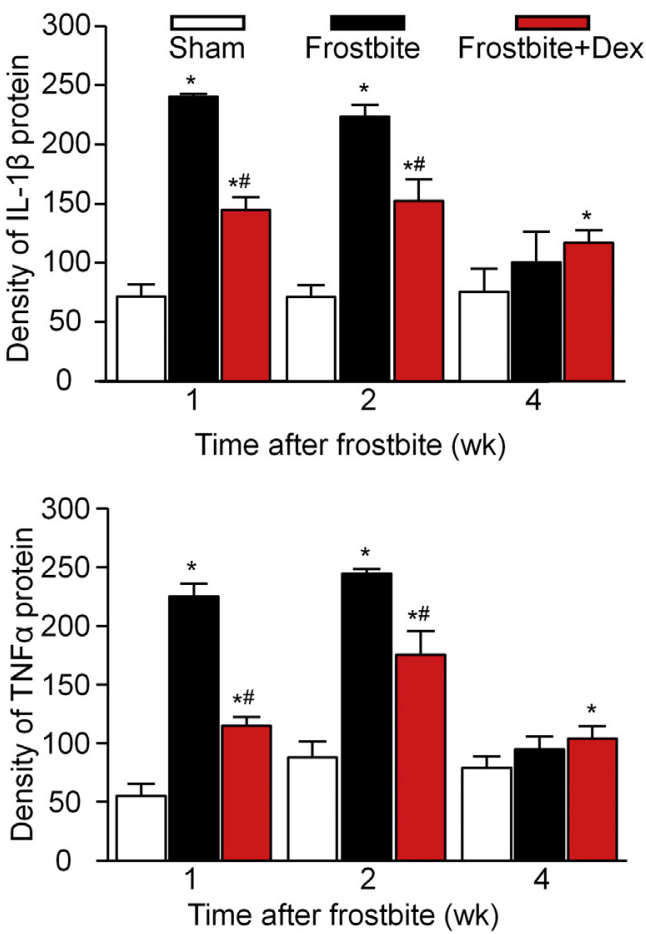

Figure 4. Representative (A) and mean data (B) showing the expression of IL- $1 \beta$ and TNF $\alpha$ proteins in the skin from sham, frostbite with dexamethasone (dex), and frostbite without dex groups of mice at different periods after the frostbite $(1,2$, and 4 wk). Data are mean \pm SD. $\mathrm{N}=6$ mice in each group. ${ }^{*} P<0.05$ vs sham. ${ }^{\#} P<0.05$ vs frostbite without dex group.

have not been recommended in spite of their potent antiinflammatory effect. Possible reasons for not recommending glucocorticoids include the potential for serious side effects with prolonged use and the paucity of clinical and animal model studies evaluating their effects in frostbite injury. We found 2 previous animal cold injury models that evaluated the effect of steroids. In a rabbit hind limb frostbite model, treatment with intramuscular cortisone (shorter acting and less potent than dex) for $5 \mathrm{~d}$ after injury was found to have no effect in reducing the extent of muscle or skin necrosis. ${ }^{52}$ In a mouse ear nonfreezing cold injury model, treatment with subcutaneous cortisone prophylactically and then daily after injury was found to inhibit inflammation and tissue damage. ${ }^{23} \mathrm{We}$ found only 1 clinical case reporting the use of steroids in the management of frostbite. ${ }^{53} \mathrm{~A}$ patient with oral frostbite after dry ice exposure was treated with intravenous hydrocortisone for $3 \mathrm{~d}$. The patient exhibited clinical improvement by Day 5 and complete resolution after 3 wk. The anti-inflammatory and wound healing effects of dex demonstrated in this frostbite study are similar to a recent study of the effects of dex in a tourniquet-induced IR animal model, which showed marked anti-inflammatory effects and improved muscle recovery. $^{31}$

As a principal component of connective tissues, collagen plays an important role in wound healing. During the repair process, fibroblast-produced collagen provides a structural framework and helps the regenerating tissue gain tensile strength. ${ }^{54}$ Treatment with dex significantly accelerated and increased collagen deposition in the proliferated tissue, promoting the formation of new skin with evenly deposited collagen throughout the injured area. These findings suggest that collagen deposition may be associated with wound healing after frostbite.

In our study, the immunofluorescence staining at $28 \mathrm{~d}$ showed that microvasculature in the frostbite without dex group was still immature and unperfused; in the frostbite with dex group, it was mature and perfused. During wound healing, vasculogenesis re-establishes blood vessels to supply and remove metabolic waste in injured tissue. ${ }^{55}$ Although the relationship between vasculogenesis and wound healing is not fully known, inhibition of vasculogenesis significantly delays wound healing. ${ }^{56,57}$ The relationship between inflammation and vasculogenesis is complex. In early wounds, macrophages produce 


\section{A. Immunofluorescent staining for CD31}

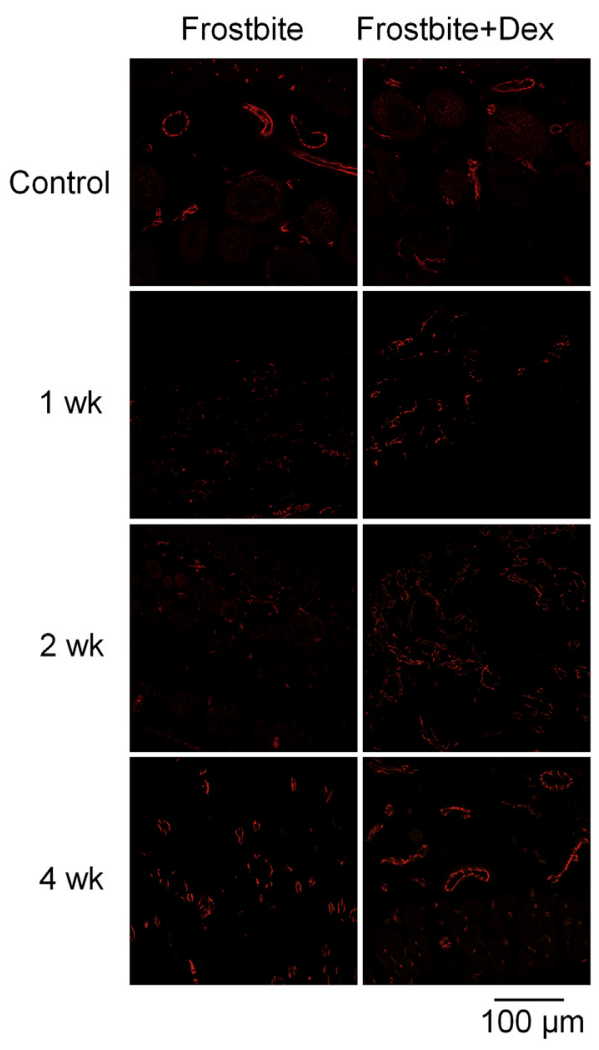

B. Western blot analysis for CD31
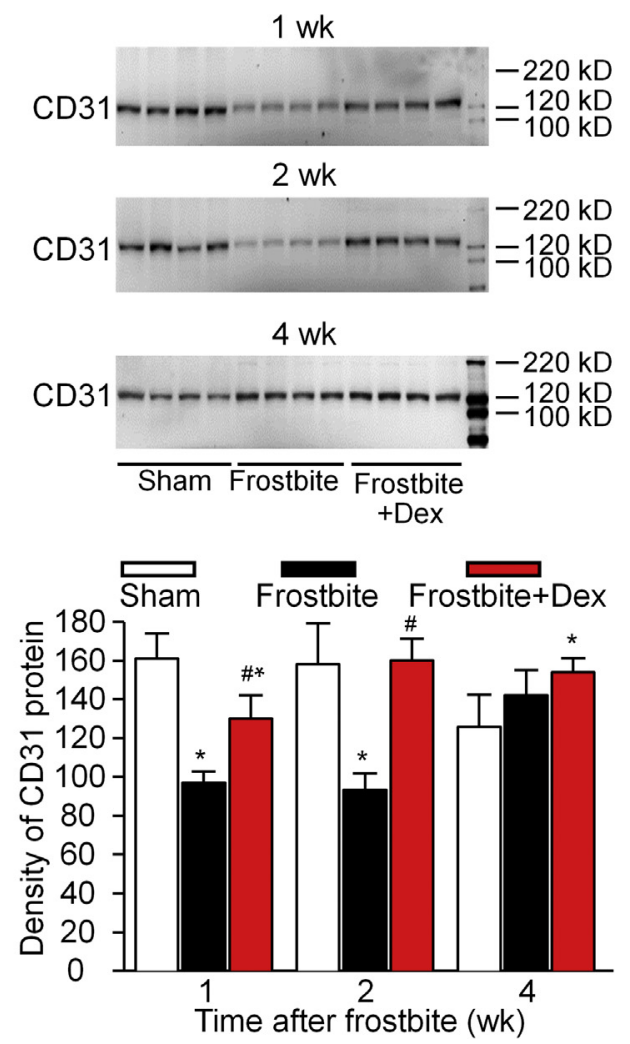

Figure 5. Expression of CD31 protein in the skin from sham, frostbite without dexamethasone (dex), and frostbite with dex groups of mice at different periods after frostbite $(1,2$, and $4 \mathrm{wk})$. CD31 protein is a vascular endothelial cell marker showing vasculogenesis. (B) Data are mean $\pm \mathrm{SD} ; \mathrm{n}=6 \mathrm{mice}$ in each group. ${ }^{*} P<0.05$ vs sham. ${ }^{\#} P<0.05$ vs frostbite without dex group.

proinflammatory mediators and chemoattractants. Later in the healing process, they ingest inflammatory leukocytes and release proangiogenic factors. Glucocorticoids have been shown to induce the anti-inflammatory and proangiogenic function of macrophages. ${ }^{58}$ However, excessive angiogenesis can lead to the formation of new blood vessels that are immature and highly permeable. Reducing inflammation has been shown to control excessive capillary growth and induce more rapid formation of a mature capillary network. ${ }^{59}$ The current study demonstrates that treatment with dex decreases inflammation, accelerates the formation of mature microvasculature, and promotes wound healing after frostbite.

\section{LIMITATIONS}

Because we used an animal model, the results may not fully apply to humans. This skin frostbite model produced a superficial ulcer rather than a blister, as is commonly seen in human frostbite. No ulceration or inflammatory response was produced by roomtemperature magnets in the sham-treated mice. It is unclear whether the ulcer injury in this model is the typical skin frostbite response in mice or if frozen magnets on frozen tissue produced the ulcer. This is a superficial skin tissue model and might not apply to deep tissue frostbite. The wound healing process in humans differs from that in mice. In humans, wounds heal primarily by the formation of granulation tissue and re-epithelization. In mice, wounds heal primarily due to rapid contraction caused by the subcutaneous muscle layer (panniculus carnosus). Although we measured inflammatory cytokines, we did not measure free radicals, which have been shown to have a relationship with cytokines and play an important role in reperfusion injury. ${ }^{4,27,60-68}$ Although dex demonstrated an expected decrease in leukocyte infiltration and levels of inflammatory cytokines, the direct relationship between the antiinflammatory effects and the increased collagen 
deposition, increased vasculogenesis, and improved wound healing needs to be further explored.

\section{Conclusions}

Using a mouse frostbite model, we demonstrated that dex improved wound healing of frostbitten skin. In addition to anti-inflammatory effects, dex treatment increased collagen deposition and stimulated vasculogenesis. These findings suggest that the use of potent anti-inflammatory agents may be an effective strategy for mitigating frostbite injury.

Author Contributions: Conception and design of the study (HT, DZ, ANB, MCW, RLM, YL); conduct of the experiments (HT, DZ, YL); data analysis (HT, DZ, YL); writing of the manuscript (ANB, RLM, YL). All authors read and approved the final manuscript.

Financial/Material Support: None.

Disclosures: None.

\section{References}

1. Heggers JP, Robson MC, Manavalen K, Weingarten MD, Carethers JM, Boertman JA, et al. Experimental and clinical observations on frostbite. Ann Emerg Med. 1987;16(9): 1056-62.

2. Reamy BV. Frostbite: review and current concepts. J Am Board Fam Pract. 1998;11(1):34-40.

3. Bourne MH, Piepkorn MW, Clayton F, Leonard LG. Analysis of microvascular changes in frostbite injury. J Surg Res. 1986;40(1):26-35.

4. Manson PN, Jesudass R, Marzella L, Bulkley GB, Im MJ, Narayan KK. Evidence for an early free radical-mediated reperfusion injury in frostbite. Free Radic Biol Med. 1991;10(1):7-11.

5. Marzella L, Jesudass RR, Manson PN, Myers RA, Bulkley GB. Morphologic characterization of acute injury to vascular endothelium of skin after frostbite. Plast Reconstr Surg. 1989;83(1):67-76.

6. Golant A, Nord RM, Paksima N, Posner MA. Cold exposure injuries to the extremities. J Am Acad Orthop Surg. 2008;16(12):704-15.

7. Ikaheimo TM, Hassi J. Frostbites in circumpolar areas. Glob Health Action. 2011;4:8456.

8. McIntosh SE, Freer L, Grissom CK, Auerbach PS, Rodway GW, Cochran A, et al. Wilderness Medical Society practice guidelines for the prevention and treatment of frostbite: 2019 update. Wilderness Environ Med. 2019;30(4S): S19-32.

9. Guyatt G, Gutterman D, Baumann MH, Addrizzo-Harris D, Hylek EM, Phillips B, et al. Grading strength of recommendations and quality of evidence in clinical guidelines: report from an American College of Chest Physicians task force. Chest. 2006;129(1):174-81.

10. Auerbach LJ, Galvez MG, De Clerck BK, Glotzbach J, Wehner MR, Chang EI, et al. A novel mouse model for frostbite injury. Wilderness Environ Med. 2013;24(2):94-104.
11. Goertz O, Baerreiter S, Ring A, Jettkant B, Hirsch T, Daigeler A, et al. Determination of microcirculatory changes and angiogenesis in a model of frostbite injury in vivo. J Surg Res. 2011;168(1):155-61.

12. Goertz O, Hirsch T, Buschhaus B, Daigeler A, Vogelpohl J, Langer S, et al. Intravital pathophysiologic comparison of frostbite and burn injury in a murine model. J Surg Res. 2011;167(2):e395-401.

13. Hu J, Li H, Geng X, Jiao L, Song H, Lou L, et al. Pathophysiologic determination of frostbite under high altitude environment simulation in sprague-dawley rats. Wilderness Environ Med. 2016;27(3):355-63.

14. Murphy JV, Banwell PE, Roberts AH, McGrouther DA. Frostbite: pathogenesis and treatment. J Trauma. 2000;48(1):171-8.

15. Rothenberger J, Held M, Jaminet P, Schiefer J, Petersen W, Schaller HE, et al. Development of an animal frostbite injury model using the Goettingen-Minipig. Burns. 2014;40(2): 268-73.

16. Bruen KJ, Ballard JR, Morris SE, Cochran A, Edelman LS, Saffle JR. Reduction of the incidence of amputation in frostbite injury with thrombolytic therapy. Arch Surg. 2007; 142(6):546-51.

17. Gonzaga T, Jenabzadeh K, Anderson CP, Mohr WJ, Endorf FW, Ahrenholz DH. Use of intra-arterial thrombolytic therapy for acute treatment of frostbite in 62 patients with review of thrombolytic therapy in frostbite. J Burn Care Res. 2016;37(4):e323-34.

18. Sheridan RL, Goldstein MA, Stoddard Jr FJ, Walker TG. Case records of the Massachusetts General Hospital. Case 41-2009. A 16-year-old boy with hypothermia and frostbite. N Engl J Med. 2009;361(27):2654-62.

19. Twomey JA, Peltier GL, Zera RT. An open-label study to evaluate the safety and efficacy of tissue plasminogen activator in treatment of severe frostbite. J Trauma. 2005;59(6): 1350-4.

20. Groechenig E. Treatment of frostbite with iloprost. Lancet. 1994;344(8930):1152-3.

21. Roche-Nagle G, Murphy D, Collins A, Sheehan S. Frostbite: management options. Eur J Emerg Med. 2008;15(3):173-5.

22. Britt LD, Dascombe WH, Rodriguez A. New horizons in management of hypothermia and frostbite injury. Surg Clin North Am. 1991;71(2):345-70.

23. Kulka JP. Microcirculatory impairment as a factor in inflammatory tissue damage. Ann N Y Acad Sci. 1964;116: 1018-44.

24. McCauley RL, Hing DN, Robson MC, Heggers JP. Frostbite injuries: a rational approach based on the pathophysiology. J Trauma. 1983;23(2):143-7.

25. Ozyazgan I, Tercan M, Melli M, Bekerecioglu M, Ustun H, Gunay GK. Eicosanoids and inflammatory cells in frostbitten tissue: prostacyclin, thromboxane, polymorphonuclear leukocytes, and mast cells. Plast Reconstr Surg. 1998;101(7): 1881-6.

26. Shapovalov KG, Tomina EA, Mikhailichenko MI, Vitkovskii I. The role of lymphocyte-platelet adhesions, 
cytokines and endothelial dysfunction in pathogenesis of cold-induced lesions. Patol Fiziol Eksp Ter. 2009;(1):39-40.

27. Vogel JE, Dellon AL. Frostbite injuries of the hand. Clin Plast Surg. 1989;16(3):565-76.

28. Curtis JR, Westfall AO, Allison J, Bijlsma JW, Freeman A, George V, et al. Population-based assessment of adverse events associated with long-term glucocorticoid use. Arthritis Rheum. 2006;55(3):420-6.

29. Fardet L, Kassar A, Cabane J, Flahault A. Corticosteroidinduced adverse events in adults: frequency, screening and prevention. Drug Saf. 2007;30(10):861-81.

30. Hanaoka BY, Peterson CA, Horbinski C, Crofford LJ. Implications of glucocorticoid therapy in idiopathic inflammatory myopathies. Nat Rev Rheumatol. 2012;8(8):448-57.

31. Zhang D, Wang D, Pipinos II, Muelleman RL, Li YL. Dexamethasone promotes long-term functional recovery of neuromuscular junction in a murine model of tourniquet-induced ischaemia-reperfusion. Acta Physiol (Oxf). 2017;219(2): 453-64.

32. Jiang S, Bailey AS, Goldman DC, Swain JR, Wong MH, Streeter PR, et al. Hematopoietic stem cells contribute to lymphatic endothelium. PLoS One. 2008;3(11):e3812.

33. Podgrabinska S, Braun P, Velasco P, Kloos B, Pepper MS, Skobe M. Molecular characterization of lymphatic endothelial cells. Proc Natl Acad Sci U S A. 2002;99(25):16069-74.

34. Kachamakova-Trojanowska N, Stepniewski J, Dulak J. Human iPSCs-derived endothelial cells with mutation in HNF1A as a model of maturity-onset diabetes of the young. Cells. 2019;8(11):1440.

35. Post PW, Donner DD. Frostbite in a pre-columbian mummy. Am J Phys Anthropol. 1972;37(2):187-91.

36. Adams-Ray J, Bellman S. Vascular reactions after experimental cold injury; a microangiographic study of rabbit ears. Angiology. 1956;7(4):339-67.

37. Bellman S, Strombeck JO. Transformation of the vascular system in cold-injured tissue of the rabbits ear. Angiology. 1960;11:108-25.

38. Bowers Jr WD, Hubbard RW, Daum RC, Ashbaugh P, Nilson E. Ultrastructural studies of muscle cells and vascular endothelium immediately after freeze-thaw injury. Cryobiology. 1973;10(1):9-21.

39. Daum PS, Bowers Jr WD, Tejada J, Hamlet MP. Vascular casts demonstrate microcirculatory insufficiency in acute frostbite. Cryobiology. 1987;24(1):65-73.

40. Delgado-Martinez J, Martinez-Villen G, Morandeira JR, Velasco R. Skin coverage in frostbite injuries: experimental study. J Plast Reconstr Aesthet Surg. 2010;63(10):e713-9.

41. Franz DR, Berberich JJ, Blake S, Mills Jr WJ. Evaluation of fasciotomy and vasodilator for treatment of frostbite in the dog. Cryobiology. 1978;15(6):659-69.

42. Hamlet MP, Veghte J, Bowers WD, Boyce J. Thermographic evaluation of experimentally produced frostbite of rabbit feet. Cryobiology. 1977;14(2):197-204.

43. Kulka JP. Vasomotor microcirculatory insufficiency: observations on nonfreezing cold injury of the mouse ear. Angiology. 1961;12:491-506.
44. Kulka JP. Cold injury of the skin. The pathogenic role of microcirculatory impairment. Arch Environ Health. 1965;11(4):484-97.

45. Quintanilla R, Krusen FH, Essex HE. Studies on frost-bite with special reference to treatment and the effect on minute blood vessels. Am J Physiol. 1947;149(1):149-61.

46. Reite OB. Functional qualities of small blood vessels in tissue injured by freezing and thawing. Acta Physiol Scand. 1965;63:111-20.

47. Spillert CR, Flanagan Jr JJ, Rosa DM, Lazaro EJ. Effect of a butter-rich diet on murine frostbite. J Invest Surg. 1988;1(2): 125-8.

48. Sullivan BJ, Leblanc MF. Effect of inositol and rapid rewarming on extent of tissue damage due to cold injury. Am J Physiol. 1957;189(3):501-3.

49. Sumner DS, Simmonds RC, LaMunyon TK, Boller MA, Doolittle WH. Peripheral blood flow in experimental frostbite. Ann Surg. 1970;171(1):116-23.

50. Weatherley-White RC, Sjostrom B, Paton BC. Experimental studies in cold injury. II. The pathogenesis of frostbite. J Surg Res. 1964;4:17-22.

51. Zacarian SA, Stone D, Clater M. Effects of cryogenic temperatures on microcirculation in the golden hamster cheek pouch. Cryobiology. 1970;7(1):27-39.

52. Lewis RB, Freytag E. Use of cortisone in treatment of experimental frostbite. Proc Soc Exp Biol Med. 1951;77(4):816-7.

53. Ohki M, Ishikawa J, Kikuchi S. Oral frostbite due to dry ice. Ann Otol Rhinol Laryngol. 2012;121(10):675-7.

54. Martin P. Wound healing-aiming for perfect skin regeneration. Science. 1997;276(5309):75-81.

55. Carmeliet P, Jain RK. Molecular mechanisms and clinical applications of angiogenesis. Nature. 2011;473(7347):298-307.

56. Rossiter H, Barresi C, Pammer J, Rendl M, Haigh J, Wagner EF, et al. Loss of vascular endothelial growth factor a activity in murine epidermal keratinocytes delays wound healing and inhibits tumor formation. Cancer Res. 2004;64(10):3508-16.

57. Streit M, Velasco P, Riccardi L, Spencer L, Brown LF, Janes L, et al. Thrombospondin-1 suppresses wound healing and granulation tissue formation in the skin of transgenic mice. EMBO J. 2000;19(13):3272-82.

58. Koh TJ, DiPietro LA. Inflammation and wound healing: the role of the macrophage. Expert Rev Mol Med. 2011;13:e23.

59. DiPietro LA. Angiogenesis and wound repair: when enough is enough. J Leukoc Biol. 2016;100(5):979-84.

60. Aizawa T, Kuwabara M, Kubo S, Aoki S, Azuma R, Kiyosawa T. Protective effect of extract of ginkgo biloba 761 against frostbite injury in rats. Plast Reconstr Surg. 2019;143(6):1657-64.

61. Bhaumik G, Srivastava KK, Selvamurthy W, Purkayastha SS. The role of free radicals in cold injuries. Int J Biometeorol. 1995;38(4):171-5.

62. Cura-Esquivel I, Delgado-Chavez EN, GarciaNarro JH, Torres-Gonzalez L, Alarcon-Galvan G, Moreno-Pena DP, et al. Attenuation of pro- 
inflammatory cytokines and oxidative stress by misoprostol in renal ischemia/reperfusion in rats. Pharmazie. 2018;73(9):537-40.

63. Ferrari RS, Andrade CF. Oxidative stress and lung ischemiareperfusion injury. Oxid Med Cell Longev. 2015;2015: 590987.

64. Halladin NL, Ekelof S, Alamili M, Bendtzen K, Lykkesfeldt J, Rosenberg J, et al. Lower limb ischaemia and reperfusion injury in healthy volunteers measured by oxidative and inflammatory biomarkers. Perfusion. 2015;30(1): 64-70.
65. Halladin NL. Oxidative and inflammatory biomarkers of ischemia and reperfusion injuries. Dan Med J. 2015;62(4):B5054.

66. Muelleman RL, Grandstaff PM, Robinson WA. The use of pegorgotein in the treatment of frostbite. Wilderness Environ Med. 1997;8(1):17-9.

67. Soares ROS, Losada DM, Jordani MC, Evora P, Castro-ESilva O. Ischemia/reperfusion injury revisited: an overview of the latest pharmacological strategies. Int J Mol Sci. 2019;20(20):E5034.

68. Su CW, Lohman R, Gottlieb LJ. Frostbite of the upper extremity. Hand Clin. 2000;16(2):235-47. 